\title{
Climate change and water management: is EU Water Law adapted to climate change?
}

\author{
P. Canelas de Castro \\ Faculty of Law, University of Macau, Macau
}

\begin{abstract}
Climate change in combination with inadequate European water resources will impact the water cycle in Europe with potentially disastrous effects. Against this background, there is an urgent need to revise the management of water resources and to develop strategies for adaptation to the changes. This paper is designed to assess whether EU water law and policy are ready to face the challenge set by climate change, whether the Water Framework Directive responses are good enough, and what can be done for adapting water resources management to climate change impacts. Generally speaking, successful adapting strategies shall be under the framework of the WFD along with its 'daughter' directives, based on the approach of integrated water resources management supplemented by measures in water-related sectors, and complemented by new typologies and screening tools, greater control and quality of information as well as a clearer relationship with other relevant legal documents for climate change adaptation.

Keywords: adaptation strategies, applicable measures, climate change, integrated management approach, Water Framework Directive, water law and policy, water management, water resources.
\end{abstract}

\section{The context: climate is changing}

It is hardly disputed any more that the climate is changing. It is also increasingly accepted that this results in insecurity and new security issues which have to be addressed. Scientific research on water conveys the distinct message that climate change will, in particular, impact the water cycle in Europe, with potentially disastrous effects. The predicted impacts will however only render worse, a more serious situation where European water resources already are under stress due to existing and increasing pressures, on the one hand, but also deficient water 
management practices, in particular an insufficient integration of such water management.

These impacts on water resources will significantly affect key economic activities such as agriculture, hydropower and energy production, tourism and navigation in large parts of Europe. But it shall equally be important to pay attention to the serious adverse impacts on biodiversity and ecosystems.

Against this background, climate change mitigation should undoubtedly remain a priority, but there is equally an urgent need to develop strategies for adaptation to the changes which climate change shall bring to the existing and potential water resources.

The main idea deriving from the realisation that there is a need to adapt water management to the climate changes is that water management approaches should be reconfigured so as to lay a particular focus on planning under uncertain conditions and a constant consideration of the potential risks and of the costs and benefits connected with those adaptation measures required by the structural apprehension that the climate is changing.

\section{The problem}

Against this context, our problem is whether European Union Water Law and Policy are ready for this adaptation challenge. Is its legal and policy architecture and foremost the Water Framework Directive (henceforth WFD) (European Parliament and Council [1]), well-equipped to meet the challenges and mutations involved? And where lay possible grounds for concern? In other words: how much adaptation does existing European Union Water Law and Policy need undergo to ensure the requisite conditions for the relevant authorities and other actors to meet the challenges of water management under conditions of climate change thus contributing to the diffusion of the security threats involved?

In order to address our problem, it seems important to firstly set the scene, namely by a broad overview of the ancient times in terms of water resources in Europe as well as the use which is made of them.

\section{Water resources: the background scenario in Europe}

The total renewable freshwater resources in Europe are of around $3500 \mathrm{~km}^{3}$ per year. These water resources are unevenly distributed between regions and river basins. Indeed, whereas there are areas where water is abundant, others are already facing water stress under present climatic conditions. According to a study by the European Environment Agency, most of the European Member States, mainly those of central and northern Europe (50\% of Europe's population), could be considered as non-water-stressed. In contrast, 9 may be considered as having low water stress (they represent around $30 \%$ of the European population; including Romania, Belgium, Denmark, Greece, Turkey, and Portugal), whereas 4 countries (a little less than $20 \%$ of population; Cyprus, Malta, Italy, and Spain) were certainly water stressed (European Environment Agency [2]). 
Water abstraction in Europe amounts to about $350 \mathrm{~km}^{3}$ water per year, i.e. $10 \%$ of the total freshwater resources. On average, more than $30 \%$ of water abstracted is used for agriculture (mainly irrigation), half of that for urban use, and a little over $11 \%$ for industry (excluding cooling), whereas energy production consumes $40 \%$ of the water available. The shares vary strongly between countries and regions, though. While in the Western European Countries, the largest percentage of abstracted water is used for cooling in energy production, the share of water abstracted for irrigation is very high in the Mediterranean region.

Another factor which should be added to this contextual picture is extreme events like floods and droughts, which are a constant concern in water management. In the latest years, Europe suffered a significant number of damaging floods, where a good percentage of the European population was affected (European Environment Agency [3]). By contrast, during drought periods, the fair allocation of water represents a great challenge and the sustainable management of water resources becomes at stake.

\section{Climate change's multifarious impacts and the need for adaptation}

Climate change will not only impact on the supply of water resources, but also on the use of and demand for water by different sectors and stakeholders.

The consequence is that the management of water resources shall have to be revised. In particular, it seems crucial to undertake an integrated management approach. Only thus shall it be possible to develop adaptation strategies that take all relevant sectors and stakeholders into account as well as the complex relationships between such sectors and actors. Only then shall it be possible to provide the requisite efficient responses.

Three main challenges to the management of water resources in particular stand out, generally, irrespective of the fact that the impacts of climate change on water resources shall likely also vary strongly between European regions.

There shall first be an increased risk of floods along coastal zones and in river beds.

Secondly, a decrease in the availability of water is also to be expected.

Thirdly, a deterioration of water quality is equally to be predicted.

As a consequence of rising sea level and changing rainfall and snowmelt patterns, flood risk - including storm surges - is expected to increase. Ensuring efficient flood protection and preventing loss of lives and damage to assets in flood-prone areas along rivers and coasts may thus become an even greater challenge due to climate change. Higher temperatures in winter mean that less precipitation will be falling as snow, and that snowmelt will be occurring earlier, thus changing the seasonal timing of river discharge and groundwater recharge. Combined with decreases in summer precipitation, this could increase the risk of droughts. However, due to the projected increase in the intensity of individual precipitation events, the risk of summer floods may increase at the same time. 
Climate change effects, in combination with unsustainable water resources management (e.g. over-consumption and pollution) in water scarcity situations, could result in severe impacts on nature and society. Therefore, drought management in Europe will have to respond to additional challenges under a changing climate (European Commission [4]).

Climate change will not affect water quantity only. Water quality shall increasingly also become an issue, excess water or low water levels also having negative impacts thereon. A possible scenario is, for instance, that the mean precipitation amount per wet day increases. This may be the case in western and northern Europe in particular. In such case, the capacity of urban sewer systems may be increasingly under strain. Additionally, a more intense runoff may lead to more pollution from diffuse sources, thus further deteriorating water quality. By contrast, fewer water in fresh water bodies shall lead to pollutants becoming less diluted, which together higher temperatures and reduced dissolved oxygen levels, shall not fail to seriously impact the ecological balance of the systems.

\section{Policy-making: how to adapt?}

In view of the above, what are the recommended policy options for adaption to climate change?

It seems that a departing consideration is that as much as human activities are strongly dependent on the availability of water resources in adequate quantity and quality, many of these activities can also adversely impact the condition of the aquatic systems. In view of this co-relation, it seems fair to hypotheses that adaption strategies that would focus on the protection of water resources shall likely redound in a higher resilience of all water-depending sectors and activities to the phenomenon of climate change. Conversely, an adaption strategy which may rely on the effective co-ordination and integration of all contribution by all the relevant sector sand activities shall certainly not fail to result in enhanced water resources management and protection. Another fundamental structural element has to do with the relevance of the risk factors to the design of "responding" adaptation strategies. Intuitively, it is crucial that these strategies beforehand adequately capture these risks. For that they have to rely on sound risk assessments. Analyses of past developments and deriving patterns are necessary. Moreover, projections of future changes and all adaptation strategies need to be based on sound risk assessments. Both existing projections of future changes and analyses of past developments should be considered in order to identify vulnerabilities and uncertainty ranges and to build robust adaptation strategies.

Climate change impacts, in particular decreases in water availability in certain regions and seasons, are likely to lead to conflicts of interests among the users. For example, if water is scarce, water use for irrigation might conflict with minimum flow regimes needed for cooling water. Adaptation may therefore require first the prioritisation of uses and then the selection of sufficient and appropriate ways of implementation. Choices may have to be made concerning the allocation of water resources, and criteria and indicators need to be 
developed on the basis of which such choices can be made. Decisions should be transparent and comprehensible to the affected sectors and the general public, in order to create acceptance among them.

Adaptation strategies should also consider the costs and the benefits of each measure and of the combinations of measures. These costs and benefits should be discussed among the different users and stakeholders.

\section{The scope of applicable measures}

A diversified list of adaptation measures of different nature (technically-oriented, land-use related, economic, information) is recommended by experts.

Technically-oriented measures. Technical adaptation can be seen as the application of technology in order to reduce the vulnerability, or enhance the resilience, of a natural or human system to the impacts of climate change.

Such measures include flood protection measures (e.g. in case of more frequent or intense flooding, defence structures may be upgraded), supply and demand measures, water saving techniques (e.g. rainwater collection and greywater recycling), water storage measures. In areas facing water scarcity, measures aiming to close the local water cycle and to encourage more efficient use of the available water should be developed and applied where possible. However, before undertaking major investments in infrastructure, all available options for adapting the operation of existing structures to changed targets and boundary conditions should be exploited. Changes in management may often provide more flexible solutions and maintain more possibilities to react to further unforeseen changes in the future. In order to identify the need for alterations of management the performance of existing systems has to be analysed regularly.

Land-use related measures. There is a strong link between changes in land use and water resources management. Land management has an influence on the ability of the soil to hold back precipitation or flood water. The sealing of large areas, for instance in urban centres, increases the risk of flash floods, while sustainably managed soils in agriculture or forestry may be able to store large quantities of water and thus act as a buffer during intense precipitation events.

Land use therefore plays an important role with respect to flood risk management. In some cases, holding back flood waters through technical measures may not be possible or may be too costly in the long term, and alternative strategies may be employed. In flood-prone areas along rivers where damage to infrastructure, buildings and property cannot be prevented at reasonable cost, it may be necessary or desirable to restrict building development, or even to consider resettlement to areas that are less at risk. Similarly, countries may prefer managed retreat along coastlines to building new dykes, or try to manage water levels and "live with water" instead of holding it back.

Economic measures. Economic instruments might play an important role in adaptation strategies. Firstly, economic incentives, such as water pricing policies and water trading schemes, can be used to encourage changes in consumer behaviour that lead to a more sustainable and efficient use of water and may help 
to reduce overall water consumption. Secondly, economic instruments can help to recover the costs of adaptation measures. They might be applied across different sectors to account for the costs of additional water use for instance by the agriculture, electricity or tourism sector.

Economic instruments might also include payments for ecosystem services (PES).

Water-related ecosystem services can be provided through land-use related measures, for instance forestation, conservation agriculture and extensification of agricultural land use, flood plain restoration, the conversion or restoration of natural land cover, or wetlands restoration. Services delivered by such measures include flood prevention, control and mitigation; regulating runoff and water supply; improving the quality of surface waters and groundwater; withholding sediments, reducing erosion, stabilising river banks and shorelines and lowering the potential of landslides; improving water infiltration and supporting water storage in the soil; and facilitating groundwater recharge.

Payment schemes may contribute to adequately valuing these ecosystem services and to encouraging the protection of such ecosystems and their capacity to provide water-related services.

Information measures. Information measures in combination with risk mapping and/or improved warning and preparedness systems are crucial to reduce vulnerability to climate change driven effects (e.g. flood risks). In addition, such information measures can create a higher awareness and acceptance among the public and stakeholders on the effects of climate change and the need to adapt to climate change (e.g. water saving).

In the case of both floods and droughts, risk mapping and zoning as well as awareness-raising among stakeholders are essential to make informed decisions about prevention and mitigation measures. Insurers may be a natural partner for policy-makers in identifying and quantifying risk, communicating risk, and developing innovative risk management proposals. Insurance schemes and financial instruments may be adapted to provide for a more equitable sharing of risk.

\section{The legal context}

Turning now more directly to the legal factor and in order to assess whether EU Water Law is ready to face the challenge set by climate change, it is important to recall, firstly, that the European Water Policy was developed over the years with the main aim to clean up polluted waters, and to ensure that clean waters are kept clean and available in a sufficient quantity $[5,6]$. Up to now, climate change impacts have therefore not been a major concern in EU water policy. The current water legislation contains only a limited number of explicit references to climate change impacts. However, it seems possible to assert that there is broad scope within the different policies to integrated adaptation efforts. We shall subsequently endeavour to substantiate this claim by analysing the major legal instrument in the field: the Water Framework Directive from this perspective. 


\section{The Water Framework Directive and its responses}

The Water Framework Directive is the main piece of European legislation in the sector and considered to have introduced a main revolution therein, mainly because it shifted the focus of policy-making from addressing problems individually to an integrated river basin and holistic management paradigm. Integrated water resources management (IWRM) as defined by the Global Water Partnership is "a process which promotes the coordinated development and management of water, land and related resources, in order to maximize the resultant economic and social welfare in an equitable manner without compromising the sustainability of vital ecosystems." It seeks to balance human and environmental needs and to co-ordinate different users' interests.

The main objective of the Directive is to ensure that by 2015 all European waters achieve "good status" - a concept which integrates chemical, ecological and morphological indicators (art. 1).

River basins are required to set up appropriate management plans (art. 13) to achieve the objectives and revise them periodically.

Climate change is not explicitly included in the text of the WFD. It is namely not explicitly classed as a "pressure". However, recent analyses have shown that climate change impacts may interfere with several of the key phases and with the delivery of key environmental objectives of the WFD. According to the same studies, climate change is likely to influence or pose risks to the characterisation of river basins and their water bodies, risk assessments to identify pressures and impacts, programmes of measures options appraisal, monitoring and modelling, and policy and management activities. On the other hand, if climate change impacts and adaptation concerns are considered in the WFD implementation process, it may provide a powerful tool for supporting climate change adaptation policies on a national and regional scale, and for integrating climate change adaptation measures in river basin management planning. Its integrative approach to management allows us to encourage the contribution to adaptation efforts by all relevant sectors and stakeholders.

Albeit not addressing climate change expressly, the WFD does make reference to "extreme events", which are relevant in the context of climate change. On the one hand, article 1 mentions the mitigation of the effects of floods and droughts as one of the purposes of the Directive, in addition to other objectives such as the promotion of sustainable water use based on a long-term protection of available water resources, and the provision of a sufficient supply of good quality surface water and groundwater. On the other one, article 4(6) classifies extreme floods and prolonged droughts as events of force majeure, in the case of which a temporary deterioration in the status of water bodies is to be allowed.

Besides, the essential conceptual and normative vector of the WFD's regime, the integrated river basin management planning process, may represent an important mechanism to support adaptation to climate change impacts. The WFD utilises the river basin as the natural unit for water management (art. 3). Synergetic, catchment-wide solutions as required by the WFD are considered 
more suitable to adaptation management than previously existing management systems. Each river basin within a Member State must be assigned to a river basin district (RBD) and the Member State must co-ordinate administrative arrangements for water management in relation to each RBD lying within its territory (art. 3).

Article 11 of the WFD obliges Member States to define and implement for each RBD and for those parts of international river basin districts falling within its territory, a summary programme of measures to address the pressures on waters. These so called Programmes of Measures (PoM) can be considered as the principal mechanism for implementing the environmental objectives required by the WFD by 2015 and the specific environmental objectives of each river basin district. PoMs have to be carried out based on the risk assessment outlined under Article 5 of the WFD. One of the topics of such assessments is flood risk of high relevance to adaptation planning.

Such programmes of measures represent a new framework for controlling activities within a RBD. These activities do not have to be water-based only, they also might include land-use activities. A Programme of Measures may include wide-ranging actions such as measures to manage specific pressures arising from forestry, agriculture, urban development, and others; control regimes or environmental permitting systems; water demand management measures; economic instruments, such as incentives, taxes on fertilisers; river restoration strategies.

A summary of the programme of measures forms part of the River Basin Management Plan (RBMP) (art. 13) which can be considered as the main reporting mechanism to the Commission and to the public (art. 20). The plan is a detailed account of how the objectives set for the river basin (ecological status, quantitative status, chemical status and protected area objectives) are to be reached within the timescale required. The RBMP have to be reviewed every six years (art. 13). At first glance, this may seem to be a quite short period compared to the time scale at which climate change takes place. However, it should be born in mind that the six year planning cycle allows each river basin to set short- and long-term targets and related measures to be achieved stepwise. At the beginning of each cycle a reflection of the previous one is required to make necessary adjustments. This does allow for a stepwise and continuous adaptation process, and for the consideration of new results from climate change projections and adaptation measures in other sectors. Hence, the cyclical review process of RBMPs provides means that procedures are amended regularly using the latest available evidence and information, which makes the management system more flexible and therefore adaptive.

Furthermore, Article 9 of the WFD introduces water pricing as a central element. It requires the design of policies having regard to social, environmental, economic effects and to the geographic and climatic conditions of the region or regions affected to address problems of water quality and quantity. This approach allows us to recover costs resulting from the adaptation to climate change, albeit with some flexibility. Including public participation and stakeholder involvement in the WFD (Article 14) allows for the balancing of 
various groups' interests for taking decisions on the most appropriate measures to achieve the objectives in the river basin management plan. The economic analysis requirement is intended to provide a basis for this, but it is essential that the process be open to the scrutiny of those who will be affected. This approach allows for informing on and raising awareness for effects of climate change. It further offers the opportunity to involve stakeholders and the interested public in the development of appropriate and commonly agreed adaptation measures.

Another important feature of the WFD is its stress on monitoring. Monitoring and risk assessment as foreseen under the WFD will provide valuable information for regional planning and development and thus create an adequate knowledge base which is a key prerequisite for the adaptation process. The collection of information under the WFD would provide information on water systems that are at, or near to, capacity, and it would help define which impacts are the result of climate change. One of the ways this would be maximized is through flood risk mapping capable of supporting policy makers in flood management.

Cross-border management and early warning systems in the international scene as required by article 3(3) are also crucial tools for adaptation.

Finally, it should not be forgotten all the WFD's stress on governance. Its constant requirement that all stakeholders actively participate in its multi-level governance of the river basin catchment districts is yet another relevant tool for ensuring the information capital required for efficient adaptative solutions to the situations created by climate change. Indeed, climate change will not only impact on the supply of water resources, but also on the use of and demand for water by different sectors and stakeholders. Integrated management approaches are thus a key prerequisite for developing adaptation strategies that take all relevant sectors and stakeholders and the complex relationships between them into account. Including public participation and stakeholder involvement in the WFD (Article 14) allows for the balancing of various groups' interests for taking decisions on the most appropriate measures to achieve the objectives in the river basin management plan. It is essential that the process be open to the scrutiny of those who will be affected. This approach allows for informing on and raising awareness for effects of climate change. It further offers the opportunity to involve stakeholders and the interested public in the development of appropriate and commonly agreed adaptation measures.

\section{Are the Water Framework Directive's responses good enough?}

These positive elements of the WFD should not hide the fact that there are also in a few instances requirements of the EU policy which may raise concern in view of a well calibrated strategy of adaptation of climate change.

This is namely the case with the demand to meeting 'good status' in all waters. This requirement many indeed hinder adaptation efforts in cases where the upgrading of certain water courses as part of flood defences is contemplated, 
for this upgrading work shall most likely often have a negative impact on the ecological condition of water systems.

It would also seem advisable that each RBD should conduct a climate change impact assessment and then formulate PoMs to implement adaptation measures; using formal cost-benefit analysis. The potential role of PoMs in reducing the secondary impacts of climate change should indeed be highlighted. Moreover, PoMs should equally pay more attention to trends related to water availability and introduce measures for mitigating water scarcity, including control of groundwater abstraction. Additional management plans for flood and drought management to face more directly the extreme events challenge could equally be conceived.

\section{Assessing the current legal developments and looking ahead}

All factors considered and pondered, it seems possible to conclude that, in the whole, the WFD does not seem to be ill-equipped to face the challenges set by climate change.

Adapting water resources management to climate change impacts requires change in management practices, land use and technology developments, so as to ensure sustainable water management. It requires the further protection of current water resources as well as the revitalisation of declined ecosystems.

The WFD along with its 'daughter' directives as well as other ongoing legal initiatives which are aimed at complementing the WFD, provide a valuable framework for adaptation. Generally, they call for an integrated and strategic planning approach that provides the unique chance to include adaptation measures in water resources management, both in the short and in the long term. The more recent flood risk management directive is equally a central element for raising awareness about the risks and vulnerability resulting from flooding and responding to these specific concerns. The actions on droughts along the pathway designed by the communication complement the trend.

Generally, it remains valid that adaptation of the management of European water resources should be based on the approach of integrated water resources management (and the complementing one of integrated coastal zone management). However, the possibilities of adaptation by water resources management only are limited.

Therefore, successful adaptation strategies have to include additional measures in water-related sectors, in particular those that are important as users and consumers of water resources, such as agriculture, electricity, navigation and tourism. The contributions from the different sectors should then be co-ordinated in overarching and integrative strategies in order to avoid conflicts and create synergies - the European Commission has a particular role to play in this regard.

In any event, for making full use of the WFDs potential to support adaptation, it would seem advisable to also obtain guidance on water resource management and climate change adaptation at the European level, if necessary by interpretative guidelines or additional legal documents which would reinforce the existing legal apparatus. 
Besides, new typologies and screening tools (a strategic climate change assessment?) may also be demanded to more rigorously identify which water bodies are most vulnerable to climate change and respond specifically to such needs.

In any event, the greater control and quality of information offered by the WFD policy system should be able to powerfully aid water managers in their efforts to adapt to changing conditions.

Additionally, a clearer relationship with other relevant legal documents for climate change adaptation should also be considered. Specifically, it should address physical impacts and adaptation, especially flooding, as in the EU Floods Directive. The issue of flooding as a major European concern is also addressed in the new proposal for a Directive on flood risk management. This Directive could represent a powerful tool for addressing increased flood risk from climate change in Europe. The flood risk management plans required by each MS should focus particularly on prevention, protection and preparedness measures. Article 4 of the proposed Directive stipulates that projected climate change should be taken into account in the assessment of future flood risk. The Flood Risk Management Directive, together with the WFD, would thus provide an instrument to take full account of climate change effects on flood risk, and, on the basis of the risk assessment and mapping, would encourage water managers to respond to challenges by means of an integrated management approach. The cyclic review process within both Directives allows for a long-term strategic adaptation process that is, however, flexible enough to also react to shorter term changes.

It should also consider inceptive instruments on water scarcity and droughts. In 2003, a water scarcity initiative was established under the WFD common implementation process. A first interim report on water scarcity and drought was adopted by the Water Directors in November 2006. The report shows that the impacts of climate change on frequency and severity of droughts is of concern among Member States, and that the WFD is seen as an important instrument for addressing drought and water scarcity management, through the implementation of water management plans and associated programmes of measures. It also outlines how other EU and national funding and policy instruments might be used for mitigating water scarcity and drought (Water Scarcity Drafting Group [7]).

Finally, it should also consider the implications of marine and coastal waters management (European Parliament and Council [8]). The European Commission is currently developing a European Maritime Policy. A Green Paper by the European Commission [9] was published in June 2006. The environmental pillar of this policy is represented by the Marine Strategy, which was launched in 2005 and consists of the Thematic Strategy on the Protection and Conservation of the Marine Environment, and of a Directive Proposal. The aim of the Marine Strategy is to achieve good environmental status of the EU's marine waters by 2021, and to protect the resource base upon which marine-related economic and social activities depend. The policy process is similar to that of the WFD. The Marine Strategy identifies climate change as one of the main pressures on the 
marine environment. The protection of the marine environment should be flexible enough to allow for an adaptation to changing pressures and impacts, which may for instance be caused by climate change. While not specifying measures to address adaptation to climate change explicitly, the Marine Strategy provides a broad framework that creates favourable opportunities for effective adaptation policies. The Commission Green Paper on Maritime Policy makes clear statements as to the challenges that will have to be addressed. It emphasises that adaptation strategies, including the organisation of sea defence, will be required to manage risks for coastal and offshore infrastructure resulting from sea level rise, increased flooding and storm surges. It also mentions that Mediterranean coastal zones are likely to be affected by changing precipitation patterns, and that an increased need for desalinisation may result from this.

The linkages with other pertinent legal instruments should be systematically reinforced to ensure the required consistency of EU water policy, henceforth also under the climate change perspective.

\section{References}

[1] European Parliament and Council, Directive 2000/60/EC of establishing a framework for community action in the field of water policy. EU Official Journal, L 327, pp. 1-72, 2000.

[2] European Environment Agency, Europe's water: An indicator-based assessment, European Environment Agency, 2003.

[3] European Environment Agency, EEA Briefing 1/2005 - Climate change and river flooding in Europe, European Environment Agency, 2005.

[4] European Commission, Water Scarcity and Drought - First Interim Report, November 2006.

[5] See Canelas de Castro, P., Novos Rumos do Direito da Água: a caminho de u ma revolução (tranquila)? Revista do Centro de Estudos de Direito do Ordenamento do Urbanismo e do Ambiente, nº1, pp.11-36, 1998; Cambiamento dei paradigmi nella legislazione internazionale e europea a tutela delle acque. Rivista Giuridica dell'Ambiente, nº6, pp. 829-853, 2006.

[6] Dellapenna, J. \& Gupta J. (eds.), Chapter 14 - European Community Water Law. The Evolution of the Law and Politics of Water, Springer, 2009.

[7] Water Scarcity Drafting Group, WFD/EUWI - MED Joint Process, Document: Water Scarcity Management in the Context of WFD, June 2006. Available at http://www.sogesid.it/allegati/convegni eventi/water_city 7 $2006 /$ WS Management.pdf.

[8] European Parliament and Council, Proposal for a Directive on the assessment and management of floods, $\operatorname{COM}(2006) 15$ final, Brussels, 18.01.2006; European Parliament and Council, Proposal for a Directive of establishing a Framework for Community Action in the field of Marine Environmental Policy (Marine Strategy Directive), COM(2005) 505 final, Brussels, 24.10.2005. 
[9] European Commission. Green Paper: Towards a future Maritime Policy for the Union: A European vision for the oceans and seas, COM(2006) 274 final, Brussels, 7.6.2006. 